\title{
Estranhas telas de sentido: a escrita de si e do outro na/pela linguagem
}

\author{
Carlos Henrique Lucas Lima* \\ Clebemilton Gomes do Nascimento** \\ Fábio de Sousa Fernandes***
}

\begin{abstract}
Resumo
Como um exercício de escrita rebelde, aliás, como toda escritura deve ser em sua potência, este ensaio pretende encetar, a partir da peculiar visão autoral dos que assinam este texto, alguns conceitos-chave para cursos de leitura e produção de textos e outros cursos correlatos que são ofertados nas universidades brasileiras. Sem pretender ser exaustivos, uma vez que ensaiamos, os autores, todos eles docentes-pesquisadores-escritores, povo de Letras e da Cultura, tecem suas compreensões acerca da língua/linguagem, da interface entre leitura e escrita, da formação docente na/para a escrita, do discurso, do(s) poder(es), da criação, da pesquisa, da ciência, da universidade, dentre outros desdobramentos e tópicos não menos relevantes. A metodologia é autoetnográfica - por falta de nome melhor - multirreferenciada e experimental, valendo-se de memórias, digressões e, sobretudo, da coragem que entendemos indissociável da prática do pensar, para criar, teorizar e tensionar a partir de uma produção de conhecimento cujos horizontes epistemológicos permitem deslocar o que se desejaria findo, assentado, pronto.
\end{abstract}

Palavras-chave: Texto. Escrita. Corpo. Vida. Sentidos.

\section{Strange screens of sense: the writing of oneself and the other through language}

\begin{abstract}
As an exercise in rebellious writing, in fact, as all writing must be in its power, this essay intends to start, from the peculiar authorial vision of those who sign this text, some key concepts for courses in reading and writing texts and other courses correlates that are offered in Brazilian Universities. Without pretending to be exhaustive, since we rehearse, the authors, all of them teachersresearchers-writers, people of letters and culture, weave their understandings about languagel language, the interface between reading and writing, writing/writing, of discourse, of power(s), of creation, of research, of science, of university, of teacher education through academic writing, among other unfolding and no less relevant topics. The methodology is auto-ethnographic - for lack of a better concept - multi-referenced and experimental using memories, digressions and, above all, courage, which we understand inseparable from the practice of thinking, to create, to theorize and, finally, to product knowledge whose epistemological horizons allow to move what was wanted, settled, ready.
\end{abstract}

Keywords: Text. Writing, Body. Life. Meaning.

Recebido: 20/03/2019

Aceito: 28/07/2019

\footnotetext{
* Universidade Federal do Oeste da Bahia (UFOB). Doutor em Cultura e Sociedade pela Universidade Federal da Bahia (UFBA). Professor Adjunto I vinculado ao Programa de Pós-Graduação em Ciências Humanas e Sociais da Universidade Federal do Oeste da Bahia (UFOB).

** Universidade do Estado da Bahia (UFOB). Doutorando em Difusão do Conhecimento pela Universidade Federal da Bahia (UFBA). Professor Assistente vinculado ao Centro de Letras da Universidade do Estado da Bahia (UNEB). Bolsista da FAPESB.

*** Universidade Federal do Oeste da Bahia (UFOB). Doutorando em Linguística pela Universidade de Brasília (UNB). Professor Assistente vinculado ao Centro das Humanidades da Universidade Federal do Oeste da Bahia (UFOB).
} 
Foi principalmente para não gritar - acabo sempre fazendo coisas para não gritar, como contar esta história - já que o grito faria ruído, e o ruído abalaria os vizinhos, esses mesmos que entram e saem, e com isso, se soubessem de mim que sou cinza e longo, e possivelmente sabem, pois deve ser justamente essa silhueta que veem através das vidraças, que tenho um quarto vazio, isso não descobririam, desde que jamais entrarão em minha casa, saberiam também que dou gritos em horas inesperadas. (ABREU, 1983, p. 72).

Na alvorada dos anos de 2019, em um agora-já que quase escapa, na expectância do desconhecido, desde uma malha discursiva que, ao mesmo tempo em que nos amedronta, nos nega o direito de sonhar, é desse lugar, da incerteza, que escrevemos este texto. Escrevemos - ou talvez seria melhor dizer o escrituramos? - para não morrer, ou melhor, como afirmou a personagem que ganha vida pela pena de Caio Fernando Abreu, "para não gritar" ou para "não deixar o sangue coagular na caneta". ${ }^{1}$ Referimo-nos a um desejo de alterar a ética da escrita e as práticas pedagógicas, consequentemente. As políticas de formação com e para a escrita, um certo modo de dizer as coisas para o mundo que dialoga não com a fantasia de uma totalidade, mas com uma "escrita-ciborgue", que "tem a ver com o poder de sobreviver, não tem base em uma inocência original, mas na tomada de posse dos mesmos instrumentos para marcar o mundo que as marcou como outras" (HARAWAY, 2009, p. 86).

Escrevemos como forma de evidenciar algo que nos parece relevante de ser dito: escrevemos porque escrever, porque dizer, falar, é o que nos faz humanos, é o que, mais do que tudo, nos faz docentes que atuam em universidades no limiar entre uma escrita para formação e uma formação pela escrita. Falar, ainda que precariamente, porquanto marcada a fala que está pelas contingências do mundo, produz, em um movimento performativo, a nossa existência. Somos profetas - aqueles e aquelas que professam — de uma crença, de um dizer espinhoso, por vezes amargo: a docência. Essa é nossa zona de enunciação que coloca em sintonia o lugar e a energia do sujeito, enunciamos na intersecção entre a teimosia e a persistência epistêmica que permite a produção de deslocamentos, deriva de uma espera, conforme aponta Roland Barthes em sua aula-texto. Proferir palavras, profanar verdades, tensionar conceitos. Nosso movimento se produz a partir de experiências que transitam entre memórias e esquecimentos que mobilizam uma força de "toda vida viva":

Há uma idade em que se ensina o que se sabe: mas vem em seguida outra, em que se ensina o que não se sabe: isso se chama pesquisar. Vem talvez agora a idade de uma outra experiência, a de desaprender, de deixar trabalhar o remanejamento imprevisível que o esquecimento impõe à sedimentação dos saberes, das culturas, das crenças que atravessamos. Essa experiência tem, creio eu, um nome ilustre e fora de moda, que ousarei tomar aqui sem complexo, na encruzilhada de sua etimologia: Sapientia: nenhum poder, um pouco de saber, um pouco de sabedoria, e o máximo de sabor possível. (BARTHES, 1978, p. 47).

Palavrear. E este ensaio é, com toda a força que lhe atribuímos, o gesto que não só nos abre para o outro como um viajante que busca o desconhecido em um road movie, mas também em um romance não escrito ou uma tragédia grega povoada de vaticínios, com seus heróis desafiando divindades, intimamente insistindo em suas derrocadas.

Escrita-aula. Experimento que nasce da necessidade de discutir, mesmo que rapidamente, porquanto na urgência do existir, no aqui e agora do intempestivo, alguns conceitos que desejamos apresentar às e aos estudantes universitários dos cursos de leitura e produção textual, ${ }^{2}$ que melhor seria se se

1 Referência utilizada em entrevista da pesquisadora e feminista negra Carla Akotirene, que menciona a teórica Gloria Anzáldua e sua reflexão sobre escrevermos com "sangue, suor e pus". Disponível em: http://portalsoteropreta.com.br/ falapreta-carla-akotirene-fala-de-seu-livro-na-colecao-feminismos-plurais-de-djamila-ribeiro/.

2 Referimo-nos, em especial, aos cursos de Leitura e Produção de Textos, Leitura e Produção de Textos Acadêmicos, Oficina de Textos em Humanidades e Língua Portuguesa, Poder e Diversidade Cultural, os quais temos ministrado junto aos Bacharelados Interdisciplinares da UFOB (Universidade Federal do Oeste da Bahia) e da UFBA (Universidade Federal da Bahia) ao longo dos últimos sete anos. 
registrasse "criação" no lugar de "produção" de textos. ${ }^{3}$ Os ciclos de criação são dinâmicos, plurais e seguem para além do controle de quem assina os textos. Assim como Gallefi (2014), nós entendemos o gesto criativo como um imperativo da vida inteligente que se renova a cada acontecimento, sendo, portanto, urgente "compreender o ato criador de maneira própria e apropriada. Para tanto, precisamos nos lançar na aventura do conhecimento e do desconhecimento de si, do Outro e do mundo em sua abertura abissal" (GALLEFI, 2014, p. 14).

Mais concretamente, queremos, aqui, falar sobre texto, escrita, discurso, língua, criação de sentidos e, principalmente, acerca do que entendemos ser a função intelectual e social da pessoa pesquisadora ${ }^{4}$ em um mundo que se faz no/pelo discurso. Já que, como ensinou Gayatri Chakra vortri Spivak (2010): não podemos, "com um floreio", abrir mão de intervir na realidade da vida. Tudo que é humano nos interessa. Somos, portanto, promotores de vida. Em uma outra escritura, talvez nos lancemos a especular sobre os papéis que, hoje, as pessoas intelectuais têm ocupado, não sem resistência ou deboche. Cabe agora, contudo, de modo a dizer algo mais sobre o tema, que, como professores de língua e cultura, como aqueles e aquelas que se lançam nesse doído ofício de escrever e escriturar a vida, não ignoramos os impactos, os deslocamentos epistemológicos que nosso dizer provoca na vida mesma, mesmo que uma vida pequena, a litlle life, como diria Hanya Yanagihara (2016).

Conforme já dito, utilizaremos, neste ensaio, memórias docentes, fragmentos de textos, insights e outras formas de referência que considerarmos relevantes para o estabelecimento de nossas ideias, a exemplo das textualidades culturais, a saber: música, cinema, literatura, teatro etc.... além de um repertório formado por autores e autoras que nos afetam, nos atravessam... Não estranhem se digredimos, se nossos pensamentos se perderem por entre autores e autoras de tempos de outrora, se nossas ideias se emaranharem a cores e sabores estranhos. Pedimos, assim, desde já, escusas.

\section{A vida: ela mesma}

A vida, ela mesma, como no título desta seção, não é algo dissociado da compreensão linguística que dela se faz. A vida é texto, mais que isso, produção de discursos, é movência de sentidos: vida e viver são questões que dizem respeito a seres culturais, que se utilizam da língua com vistas a significar a existência. Enfatizamos isso, sobretudo, em tempos de fascismo, porque há uma rede de poder que anseia pela aniquilação, pelo apagamento das diferenças, pelo expurgo do outro, pelo retorno ao determinismo biológico, pela proliferação de discursos que patologizam corpos/vidas dissidentes, inconformes. Falar, ou seja, produzir discursos é absolutamente existir para o outro, como nos disse Fanon (2008).

Assim, diz-se que há uma dissociação entre o que é biológico e o que é cultural, entre o que é carne e o que é espírito - e espírito, aqui, diz respeito à intelecção, ao pensamento, àquilo que escaparia à nossa tão frágil matéria orgânica. É como se o biológico — vindo de um Além, de um lugar outro, metafísico, fora da cultura — pudesse existir por si só. "Pequeno Príncipe" solitário em seu planeta...

Esse entendimento, definitivamente, é rechaçado por nós. A cultura é compreendida aqui como um conjunto de significantes e significados que circundam o mundo, ou seja, "um conjunto de sistemas

\footnotetext{
3 No decorrer do texto, usamos uma ou outra expressão, ou as duas juntas, de modo a pensar a produção como forma de criação, mas também a disputa em si dos dois termos, através de um exercício de rebeldia com a institucionalidade, além da própria mobilidade de sentido dos signos linguísticos.

4 A opção por utilizar a construção discursiva "pessoa pesquisadora" marca uma tentativa de enfrentamento do sexismo na linguagem, que produz uma ciência androcêntrica e que tem como principal marca o masculino genérico, que é uma criação linguística marcada pelo poder. Assim como nós, pesquisadoras e pesquisadores vêm buscando construções discursivas, artifícios linguísticos que visam a minimizar a violência das formas linguísticas binárias. Nesse sentido, "pessoa pesquisadora" parece razoável no sentido de representar as múltiplas identidades dos sujeitos sem apagar as singularidades e existências.
} 
simbólicos que, de uma forma ou de outra, prescreve e normatiza a conduta humana e também uma forma de violência imposta à natureza" (REIS, 1992, p. 2), "produzindo" o existir, por ser e se fazer "palavra", destarte, a vida adquire sentido em uma lógica que (con)forma a própria humanidade.

Estejamos atentos à linguagem que se pretende neutra e genérica, pois ela pode funcionar no sentido de enfraquecer a importância da criação de conceitos que podem gerar impactos na transformação social, além de des-historicizá-los, despolitizá-los e descontextualizá-los (D’SOUZA, 2010). Destacamos essa estratégia, uma vez que, lamentavelmente, forças reacionárias teimam em apontar uma suposta "naturalidade" — e "neutralidade" — do corpo e do humano. E esse natural, marcado propositalmente em itálico, é a forma que encontramos de burlar — de rir mesmo — da ingenuidade desses fiscais da norma, senhores e senhoras do encapsulamento do existir (como se isso fosse, de fato, possível...). Reiteramos: somos carne, mas, ao mesmo tempo, somos cultura, ou melhor, e mais especificamente, somos carne-cultura. Palavra. Texto. Dizer. D(e)is-curso: o curso da vida, percurso, movimento, devir.

A vida, ela mesma, e se pudéssemos acessá-la sem a mediação decisiva da linguagem, seria algo... seria algo que não conseguiríamos nem precisar, já que, como cremos que evidente ficou, somos seres culturais. Linguísticos, sígnicos, irremediavelmente imersos no simbólico. O texto para nós é um modelador de projetos de vida. Não há vida, portanto, sem a mediação da linguagem. De seus processos de significação, de sua significância, quer dizer: os atributos que possui ela de fazer algo manifestar existência, concretizar-se no mundo. Se lermos com atenção o "Mal-estar na cultura", de Sigmund Freud (1930/1996), veremos que o humano é inaugurado quando da sua entrada no linguístico. No simbólico, se quisermos acessar outros repertórios teóricos, outros saberes e sabores existenciais.

É a capacidade, portanto, de significar a vida, de dotá-la de sentido, que nos transforma nessa coisa incrível que chamamos humanidade. Mesmo que, por vezes, essa mesma humanidade, invocando discursos de pureza e originalidade, tente destruir exatamente aquilo que lhe faz tão fantástica: a sua diversidade, a sua diferença. Exemplos disso abundam, mas não vamos, neste texto, a eles nos deter. Vale apontar, contudo, que, não por acaso, discursos de pureza — racial e linguística — investem na negação do múltiplo, ou seja, daquilo que prolifera e transborda.

Mediar o processo de produção e leitura de textos na universidade como espaço de produção e difusão de conhecimento é, principalmente, afirmar a primazia da língua em nossas existências, como elemento de constituição de realidades. É com ela, a língua, que, mais do que nos expressarmos e comunicarmos, ${ }^{5}$ nos fazemos gente. Que no nosso compromisso de produzir saberes localizados sejamos também ator e agente, como lembra Donna Haraway (2009, p. 36): "não como uma tela, ou um terreno, ou um recurso [...] nunca como um escravo que encerra a dialética apenas na sua agência e em sua autoridade de conhecimento 'objetivo"'. Pessoa. Coisa essa que está em falta nos últimos tempos... Depois das máquinas das indústrias dos séculos XVIII e XIX, das revistas da "mulher moderna" (à la Reader's Digest), dos freeshops de aeroportos, chegou o tempo das redes sociais e dos vídeos de YouTube e, claro, das fakenews, ${ }^{6}$ que, violentamente, nos (trans)formam em uma humanidade cada vez mais solitária e narcísica, cada vez mais monocromática, regulada, presa a uma tela retangular de valor obsceno.

Mas, mesmo na crítica, quer dizer, muito embora digamos que a humanidade que está em projeto — e se está em projeto, pasmem, há disputa! — se parece, cada vez mais, com qualquer coisa que

\footnotetext{
5 Pretendemos aqui negar, em absoluto, o caráter comunicacional da língua/linguagem, de Roman Jakobson. É certo que usamos esses termos evidentemente para esse fim, pois sabemos que a linguagem excede à mera comunicação ou simples "entrega de uma mensagem".

6 Destacamos que as fakenews, as notícias falsas, calcadas em distorções e mentiras que intencionalmente falseiam os acontecimentos, produzem uma certa subjetividade. Que tipo de subjetividade seria essa constituída a partir de notícias falsas? Eis uma pergunta relevantíssima para outra investigação.
} 
não o humano, os exemplos que demos evidenciam o caráter daquilo que funda a vida: o discursivo. Linguístico. Concluímos, então, que não há humanidade sem linguagem, sem língua, sem discurso. A-vida-mesma-feita-texto. Por ora, vale dizer que a linguagem, ou seja, a-vida-feita-sentido, é parte de nosso interesse na formação de sujeitos críticos, politicamente engajados na arena do jogo discursivo, e não, como se poderia supor, sujeitos que mecanicamente manejam uma certa gramática — normativa, prescritiva, por óbvio.

\section{O humano com a língua para fora}

A língua, como sistema, tal qual postulou Ferdinand de Saussure (1999), de onde tiramos os conceitos de língua e fala, de significante e significado, seria arbitrária, geométrica, opaca, uma imposição, como diria Michel Foucault, dos sistemas de poder, dos grupos de interesses, que dizem o que pode e o que não pode, que estabelecem os limites do existir. As fronteiras do ser. A língua, na perspectiva saussureana, é previsível, arbitrária, nesse sentido, seus referentes, todos eles externos à vida mesma, independem das dinâmicas sociais. Quer dizer, para Saussure, o ato de nomeação das coisas que nos rodeiam não guarda relação alguma com a coisa em si — daí o conceito da arbitrariedade do signo, a que já nos referimos. Uma coisa só se chama uma coisa porque assim o dizemos. E dizemos "coisa" não gratuitamente: o interesse é que o/a leitor(a) substitua essa palavra como bem lhe aprouver.

Saussure (1999) aparece neste texto, em um primeiro momento, como apoio para compreender o conceito de língua, qual seja um sistema binário e normativo. Em um segundo momento, temos a virada funcionalista, é verdade, juntamente com Mikhail Bakhtin (2003), que nos ensina que a língua é a organização social do discurso, isto é, é elaborada, feita, organizada pelos humanos que vivem em sociedade. Aliás, é Bakhtin quem se volta para a existência do sujeito concreto. Viver, portanto, é uma ação que coloca em diálogo o eu e o outro. Assim, língua, recapitulando, é um produto humano e, como produto, é artificial. Como propõe Bakhtin, a língua é viva, concreta e tem a propriedade de ser dialógica. É algo criado. Produzido. No sentido de tecnologia.

Se a língua, então, é produto das sociedades, um engenho humano, e se as sociedades, como por todas e todos nós é sabido, mudam, se transformam, a língua, de sua parte, também se modificará. Definições equivocadas, segundo entendemos, de língua como algo puro, um arianismo linguístico, não fazem o menor sentido. É como tentar prender Cérbero, o cão de três cabeças da mitologia grega, em uma jaula de papagaio...

A língua, então, é a mais humana das criações da humanidade. Como afirmou Michel Foucault (2012, p. 10): “O discurso não é simplesmente aquilo que traduz as lutas ou os sistemas de dominação, mas aquilo porque, pelo que se luta, o poder do qual nos queremos apoderar”. O discurso é, sobretudo, o uso da linguagem como uma forma de prática social, vida em movimento. Esse jogo de sentidos que é o discurso pressupõe um processo de ação e representação, um jogo dialético que coloca em cena sujeitos submetidos a uma dimensão sócio-histórica. É dessa forma que o discurso, ou, de maneira ampliada, a língua - não simplesmente o meio, o instrumento, a ferramenta por meio da qual nos movemos no mundo, mas, e, principalmente, a coisa mesma - torna a vida vivível, isto é, possível.

\section{Cartografias para o desconhecido}

De um modo geral, os cursos de criação de textos que ministramos, bem como toda e qualquer tentativa de mediar, didaticamente, nas salas de aulas de graduação, os processos de leitura e produção 
de discursos e textualidades, estilisticamente reconhecidos como acadêmicos, acabam por assumir uma feição reprodutiva de fórmulas e malfadadas tentativas de "aprender" a ler e a construir textos, como se isso resultasse de uma perfeita simetria entre fórmulas, algoritmos, fusão de elementos químicos e experimentações realizadas em laboratórios, ordenadas por programas rígidos, planos de trabalho neutros, puros, e cujas hipóteses são, desde já, teses elucubradas por arrogante cientista.

Desde as maçantes aulas de cursinhos pré-vestibulares, com suas regras, fórmulas, cálculos que se querem precisos, até estruturas encapsulares ensinadas como dogmas em alguns cursos das áreas de Humanas e mesmo de Letras, o ensino da produção de textos tem sido isso mesmo: mera produção. Um "Tempos Modernos" da escrita. Nossa concepção, na contramão de tais perspectivas, advoga pela criação no processo de escritura-ação. E a criação, diferentemente da produção, tem um único comprometimento: consigo mesma. Palavras bailando pelos ares. Textos rodando para lá e para cá. Discursos (con)formando existências, fundando seres. Fazendo-se carne.

Essa mofada noção de produção, de (suposta) ciência, gestada pelo anseio da modernidade como um projeto de mundo maquínico e perfeito, ainda ronda, tal qual um ladrão à noite, os espaços de produção de saberes das universidades contemporâneas. Essa noção de universidade-fábrica, como reflete Cássio Hissa (2013), é tola (apesar de pujante e impositiva) porque ignora a potencialidade das máquinas de se reinventarem, de se acoplarem em outros dispositivos e de escaparem do receituário de seus manuais de instrução. O que queremos dizer, então, é que, mesmo na lógica da máquina, haveria deslizamento. Sonho, ou melhor, pesadelo perturbador do humano: máquinas criando máquinas, uma espécie de "Matrix" que escapa à programação inicial e se metamorfoseia em uma versão 2.0.

Nos cursos de criação de textos nas universidades em que temos ministrado aulas, nos últimos anos, testemunhamos esse movimento de, a despeito da maquinaria institucional, uma força que, por vezes, nos exaspera, as e os estudantes rebelarem-se na e pela palavra. Criam formas moventes de texto. Surpreendem a coisa-que-se-queria-pronta. Inauguram porvires. Nós defendemos, nesse sentido, que, mesmo que a instituição nos diga "é preciso ensinar os meninos a ler e a escrever", 7 nós retrucaremos: "é preciso escriturar a vida, enchê-la de palavras, engravidá-la de sentidos. É preciso".

Escrevemos projetos porque ansiamos afetar a realidade. Há algo nela em desajuste, fio desencapado, válvula perfurada, display impreciso, risco, curto-circuito. Sismo. Tudo nasce de uma ferida aberta, uma dor de mundo. Começamos a afetar esse mundo que nos incomoda quando sua imprecisão em movimento é, por nós, investigadores-curiosos-artesãos, perscrutada pela formulação de problemas. Eles não estão apenas lá, à espera do sagaz cientista, cujo olhar supostamente privilegiado e dotado de sentidos superiores desvela. Acha. Descobre. Pensar sobre os problemas que nos afetam é também, por mais paradoxal que possa parecer, criá-los, tornando-os matéria e estado de arte bruta. É preciso "criar problemas" e, mais do que isso, saber como criá-los. A linguagem, então, materializa os problemas que lá estão, mas só passam a estar quando demiurgicamente os produzimos. Deuses das palavras. Um fiat lux do texto.

Pensar para além da noção de universidade-fábrica é pressupor que o texto de ciência não é, definitivamente, um sanduíche milimetricamente produzido por uma rede de fast-food. O saber que é produzido a partir de um processo de investigação científica, em qualquer área do conhecimento, é textualizado, textualizável, portanto, passível de ser metaforizado, falseado, contestado e traduzido. Produzir conhecimento requer ousadias e criatividades. A escrita do mundo é como o ofício do pirata: um trabalho que é, por essência, indissociável do perigo. Do risco que representa o desconhecido mar. O que será que me reserva o horizonte? O que há para além da linha que escapa aos olhos nus?

\footnotetext{
7 Menção à fala de uma gestora institucional que, à época de nossa posse como docentes em instituição pública federal de ensino, pretendia delimitar o objeto de nossa docência. A frase, em nossa opinião, embrutecedora da vida, parte do princípio de que os e as estudantes seriam analfabetos, ocos de palavras, desprovidos de textos, em uma reedição da tábula rasa jesuítica do período colonial. Rebelamo-nos contra esse entendimento. Por certo.
} 
Os riscos podem ser calculados, planos podem ser traçados, hipóteses formuladas, mas a abertura para a inovação se aproxima mais do torto, do subversivo - e não subserviente, do que de teorias, métodos e cronogramas aprovados por conselhos "superiores" (a quem não sabemos...). Na terra firme, como bem asseverou Renato Janine Ribeiro (1999), não se produz conhecimento. É no risco, no mar agitado, no para-além-das-ilhas-acadêmicas, que se faz o saber. "Navegar é preciso; viver não é preciso". O conhecimento que estamos pretendendo construir, nosso modus operandi, se modela nas bordas, nas inflexões, nos bifurcamentos, nos tangenciamentos, nas fissuras e rasuras da razão canônica e dos discursos dominantes.

Mas, então, é tudo caos e imprevisibilidade? Silhuetas científicas que caminham em uma noite escura? Absolutamente. Somos constituídos por linguagem e a utilizamos para formular problemas e criar projetos, roteiros que, como a realidade/vida humana, precisam ser reavaliados constantemente, em um processo que não é solitário, ${ }^{8}$ mas que se retroalimenta por meio de diálogos com as nossas redes: complexos, diversificados, móveis e, por vezes, conflituosos e contraditórios. "Não esperem de mim coerência", teria dito Foucault a certa altura de sua vida.

Nossos projetos são cartografias, esses mapeamentos móveis que se fazem no momento mesmo do movimento, rumo ao desconhecido, porque é insuficiente e arrogante propor a elaboração de respostas definitivas para os problemas que perscrutamos. A abertura para esse incógnito não significa caminhar vendado sobre uma corda ligando montanhas, mas estabelecer estratégias para que tal ligação entre esses dois blocos possa ser estabelecida. Nossos projetos precisam incluir o desejo de criar e a rebeldia para contestar aquilo que está assentado. Para mover as terras endurecidas pela falta de água. Para revolver o terreno. Traçadas as estratégias, compreendida quão criativa e inventora é cada etapa do processo, mergulhamos na investigação cientes de que a escrita é tanto interpretação aguda quanto um labor tecelão. Nos versos de Olavo Bilac: "Longe do estéril turbilhão da rua,/ Beneditino, escreve! No aconchego/Do claustro, na paciência e no sossego,/Trabalha, e teima, e lima, e sofre, e sua!".

As máquinas que se acoplam durante essa trajetória explicitam o caráter politeísta e polilógico da linguagem. Cada texto que lemos, cada experiência a que nos submetemos, cada confronto e escolhas realizadas nas mais diversas etapas de nossa vida se conectarão de forma complexa e decisiva para nossa produção/criação textual. A linguagem, na perspectiva bakhtiniana, é produzida em contextos históricos, políticos, sociais e culturalmente situados (seríamos sujeitos de(formados) por essas entrópicas decisões do universo?). Retomamos, aqui, a noção de redes, de partilha de saberes e experiências. Ser uma pessoa produtora/criadora de textos desde o espaço acadêmico requer uma atitude atenta e desconfiada com todo e qualquer discurso que se pretende representativo da "realidade" objetiva. Assim, como um prisma, um feixe de luz, a "realidade" apresenta gradações e intensidades múltiplas de singularidades irredutíveis. A ideia de rede ultrapassa o mais aparentemente solitário trabalho de gabinete que, ainda assim, é um exercício de grupo, como os galos que tecem as manhãs com seus cantos, na poesia de João Cabral de Melo Neto.

Como reconhece Bell Hooks (2010), apesar da proliferação de discursos contrários, continuamos a acreditar na sala de aula como o espaço privilegiado do protagonismo de vidas, lugar de paixões, em que o Eros, como potência criativa, tem lugar. Queremos continuar a alimentar aquela paixão sempre utópica - porquanto força que nos mantém em movimento, no qual mente-corpo sentem juntos e conhecem o desejo. Nesse aspecto, para nós, docentes-pesquisadores, a aula é o ponto de partida que produz ressonâncias afetivas no seu devir musical e produtor de sentido para nossas existências. Compreendemos a aula a partir de Deleuze:

Uma aula não tem como objetivo ser entendida totalmente. Uma aula é uma espécie de matéria em movimento. É por isso que é musical. Numa aula cada grupo ou estudante pega

8 Tal qual este texto, escrito a seis mãos. 
o que lhe convém. Uma aula ruim é aquela que não convém a ninguém. Não podemos dizer que tudo convém a todas as pessoas. As pessoas têm de esperar. Obviamente, tem alguém meio adormecido, porque ele acorda misteriosamente no momento que lhe diz respeito. Uma aula é emoção. É tanto emoção quanto inteligência. Sem emoção não há nada, não há interesse algum. Não é uma questão de entender e ouvir tudo, mas acordar em tempo de captar o que lhe convém pessoalmente. É por isso que um público variado é tão importante. Sentimos os deslocamentos dos centros de interesses que pulam de um para o outro. Isso torna uma espécie de tecido esplêndido. Uma espécie de textura. (DELEUZE, 1988. Fragmento da entrevista "Obecedário de Gilles Deleuze", seção "P de Professor").

O ponto de chegada em uma pesquisa, cuja rotina é a de um processo de leituras, escritas, experimentações, testagens, revisões e elaboração de sínteses, de modo geral, é ilustrado com uma reflexão sobre os resultados. Essa seção não é (ou não deveria ser), de modo algum, um ponto final, mas um espaço de tensão criativa que, inexoravelmente, será confrontado nos diálogos que realizamos com o mundo: uma dialética, em sentido pós-estruturalista, na qual a conclusão, que não é o fim, se transforma em uma nova tese a ser desmontada e matéria fertilizante para novas ideias e inflexões.

Como teoriza Bakhtin (2003), cada vez que produzimos enunciados, estamos, a propósito, participando de um diálogo com outros discursos. A criação de uma escrita acadêmica é, portanto, forjada a partir de uma proliferação de muitas vozes sociais composta pelas autoras e autores com as/ os quais dialogamos. Nesse sentido, o discurso acadêmico, como gênero textual, é cercado de uma certa rigidez que, de certo modo, limita o jogo subjetivo da linguagem. É preciso, então, também renovar, e por que não dizer, estranhar as formas de fazer os textos acadêmicos. Leandro Colling (2013; 2018), pesquisador do campo dos estudos de gênero, sexualidades e artivismos, em muitas de suas publicações, insiste nisso: no estranhamento, na queerização do texto (que se quer) científico, duro, certo e correto, protegido pelos guardiões do "Saber Acadêmico" — que vai em maiúsculas como forma de burla.

Esse tipo de movimento de insurreição, defendemos, não precisa — como se isso fosse comum! se restringir à pós-graduação. Pode ele, sem dúvidas, ter lugar nas salas de aula também de graduação. É preciso compreender a potência, como dissemos ao longo deste ensaio, demiúrgico dos textos. Se a compreendemos, conseguimos, com ela, nos deparar com o desconhecido. No sentido do queer mesmo: com o estranho. Aquilo que não se consegue nomear.

A produção de textos nas universidades, nas nossas experiências nos Bacharelados Interdisciplinares, por exemplo, nos convida a uma análise, ainda que breve, das práticas de escrita de textos nas escolas de Ensino Médio também, especialmente as públicas. A pesquisa realizada em conjunto com bolsistas de iniciação à docência (alunos do curso de Letras em formação), em um projeto financiado pela CAPES (NASCIMENTO; PEREIRA, 2017), o qual coordenamos nos últimos anos, revela-nos os dilemas, tensões e desafios que envolvem a escrita e a reescrita de textos em aulas de "produção" textual na Educação Básica. Tal experiência nos permitiu ainda questionar o significado de certas ações didáticas na formação pessoal e profissional dos futuros professores e professoras do curso de Letras, o caráter confinante das práticas de leitura vigentes e como esses espaços colocam em jogo identidades instituídas e relações de poder.

\section{O desconhecido}

A escrita de textos, então, abre para o desconhecido. O estranho. Aquilo que surpreende e, por vezes, choca. É preciso que, como docentes, estejamos abertos a essa diferença incessante. Que prolifera. A diferença pura (WILLIAMS, 2013): algo que está em constante processo de diferimento, de resistência à definição. E assim são os textos na sua pluralidade e multimodalidade. Neste ensaio, 
pretendemos apontar isso e mais: reivindicar a constituição eminentemente textual de nossos corpos e existências. Apontar o caráter cultural da vida e de sua dependência da língua e da linguagem. Procuramos, também, refutar o conceito de "produção" de texto, associando-o à universidadefábrica, à mecanização de algo que deve ser puro movimento, o que chamamos de cartografia para o desconhecido. Como seres culturais, produtos e produtores, criaturas e criadoras de sentidos no mundo, por meio das palavras, apenas a exposição violenta, profunda, a textos, discursos e práticas de (re)escrita nos habilitará a manejar, com maior êxito, ou sucesso, algo que nos define como humanos: a linguagem. Apostamos em uma ordem ética da escrita e reescrita com as alteridades na qual o jogo do outro nos afeta, nos melhora. Que façamos cada um de nós a nossa própria e apropriada cartografia. Aqui ousamos tecer alguns rizomas de nossos itinerários ao falar do ser-sendo, fazendo o que desejamos ser. Mas, sem esquecer, como assevera Dante Gallefi (2014), que a cartografia cria fissuras para o acontecimento dialógico e polilógico criador, ou seja, o sentido da cartografia está na sua recepção pública ao permitir que outros a vejam e a leiam em suas nuances e ressonâncias afetivas, fenômeno este que parte da compreensão de que todas e todos são um e um é todas e todos.

Encerramos com a menção ao texto de Caio Fernando Abreu, cuja escrita forjou as subjetividades destes que escrevem aqui, ou melhor, que escrituram: este ensaio ocupa o lugar do grito. Escrituramolo, pois, para não gritar.

\section{Referências}

ABREU, Caio. O triângulo das águas. São Paulo: Nova Fronteira, 1983.

BAKHTIN, Michail. Estética da criação verbal. 4. ed. Tradução de Paulo Bezerra. São Paulo: Martins Fontes, 2003.

BARTHES, Roland. Aula (aula inaugural da cadeira de semiologia literária do Colégio de França pronunciada dia 7 de janeiro de 1977). Tradução de Leyla Perrone-Moisés. SP: Ed. Cultrix, 1978.

COLLING, Leandro. A igualdade não faz o meu gênero. Em defesa das políticas das diferenças para o respeito à diversidade sexual e de gênero no Brasil. Contemporânea - Revista de Sociologia da UFSCar, v. 3, pp. 405-28, 2013.

COLLING, Leandro. A emergência dos artivismos das dissidências sexuais e de gêneros no Brasil da atualidade. Sala Preta, 18(1), 152-167, 2018.

DELEUZE, Gilles. O Abecedário de Gilles Deleuze, seção "P de Professor”. 1988. Disponível em: https://www.facebook.com/watch/?v=349286368767959. Acesso em: 06 de maio de 2019.

D' SOUZA, Radha. As prisões do conhecimento: pesquisa ativista e revolução na era da globalização. In: SANTOS, Boaventura de Souza (org.). Epistemologias do sul. São Paulo: Cortez, 2010 .

FANON, Frantz. Pele negra, máscaras brancas. Tradução de Renato da Silveira. Salvador: EDUFBA, 2008.

FOUCAULT, Michel. A ordem do discurso: aula inaugural no Collège de France, pronunciada em 2 de dezembro de 1970. Tradução de Laura Fraga de Almeida Sampaio. São Paulo: Edições Loyola, 2012.

FREUD, S. (1930). O mal-estar na civilização. In: FREUD, S. Edição Standard Brasileira das Obras Psicológicas Completas de Sigmund Freud. Rio de Janeiro: Imago, 1996. v. 21.

GALLEFI, Dante Augusto. Criatividade como transformatividade humana própria e apropriada. In: MACEDO, Sidnei; GALLEFI, Dante; BARBOSA, Joaquim. Criação e devir em formação: maisvida na educação. Salvador: EDUFBA, 2014. p. 11-61. 
HARAWAY, Donna. Manifesto Ciborgue: ciência, tecnologia e feminismo-socialista no final do século XX. In: SILVA, Tomáz Tadeu. (org.) Antropologia do ciborgue: as vertigens do pós-humano. Belo Horizonte: Autêntica, 2009. p. 33-118.

HISSA, Cássio Eduardo Viana. Entrenotas: compreensões de pesquisa. Belo Horizonte: UFMG, 2013.

HOOKS, Bell. Eros, erotismo e o processo pedagógico. In: LOURO, Guacira Lopes (org.). O corpo educado: pedagogias da sexualidade. 3. ed. Belo Horizonte: Autêntica Editora, 2010. p. 113-123.

NASCIMENTO, Clebemilton; PEREIRA, Cleide S. A. O jogo discursivo da escrita e reescrita na aula de produção textual. Rev. EntreLetras, Tocantins, v. 8, n. 2, p. 326-339, 2017.

REIS, Roberto. Cânon. In: JOBIM, José Luís (org.). Palavras da crítica. Rio de Janeiro: Imago, 1992. p. 65-92.

RIBEIRO, Renato Janine. Não há pior inimigo do conhecimento do que a terra firme. Tempo Social Rev. Sociol, São Paulo, p. 189-195, 1999.

SAUSSURE, Ferdinand de. Curso de Linguística Geral. Tradução de Antônio Chelini, José Paulo Paes, Isidoro Blikstein. 25.ed. São Paulo: Cultrix, 1999.

SPIVAK, Gayatri Chakravorty. Pode o subalterno falar? Tradução de Sandra Regina Goulart Almeida e Marcos Pereira Feitosa, André Pereira Feitosa. Belo Horizonte: Editora UFMG, 2010.

WILLIAMS, James. Pós-estruturalismo. 2. ed. Petropólis, RJ: Vozes, 2013.

YANAGIHARA, Hanya. Uma vida pequena. Tradução de Roberto Muggiati. Rio de Janeiro: Editora Record, 2016. 